\title{
Surgery and radiotherapy for early breast cancer
}

\author{
Better local control not yet translated into improved survival
}

Although prospective randomised trials have shown that treating early breast cancer by conservative surgery and radiotherapy is as effective as mastectomy, revelations of scientific misconduct in the largest of these trials last year caused widespread public concern. ${ }^{1}$ Media reports that one contributor to the United States national surgical adjuvant breast and bowel project had altered some of his data suggested that patients could no longer trust the trial's conclusions, and it left many patients angry and frightened that they had not been treated appropriately. Three articles in last week's New England fournal of Medicine provide reassurance about the efficacy of breast conserving treatment. ${ }^{2-4}$

The first article is an audit of the trial from the United States National Cancer Institute. It reports that $97 \cdot 5 \%$ of the data were entered correctly. ${ }^{2}$ The second article is a reanalysis of the audited data after 12 years of follow up. The trial compared the outcome in women with early breast cancer after total mastectomy alone or after lumpectomy with or without radiotherapy. The reanalysis shows no significant difference in survival between the three groups, although the incidence of ipsilateral tumour recurrence was 35\% in the group treated by lumpectomy alone compared with $10 \%$ in the group treated with lumpectomy and radiotherapy. ${ }^{3}$ The third article is a meta-analysis of randomised trials of radiotherapy and surgery in early breast cancer. ${ }^{4}$ Based on data from a total of 4891 women in nine trials comparing mastectomy and breast conservation with or without radiotherapy, it confirms that there is no significant difference in overall survival at 10 years. Although the meta-analysis showed that radiotherapy did seem to reduce the risk of death from breast cancer (odds ratio 0.94 (95\% confidence interval 0.88 to 1.00 ), $P=-0.03$ ), this was counterbalanced by an increased risk of death from other causes (odds ratio 1.24 $(1.09-1 \cdot 42), P=0.002)$, leading to no difference in overall survival. ${ }^{4}$ The excess of deaths from causes other than breast cancer seemed to be much greater in women aged over 60 at the time of treatment.

There are two major concerns that limit the relevance of this meta-analysis to current clinical practice. Firstly, the radiotherapy techniques and schedules varied substantially between different trials included in the analysis, and the majority do not match those now used. Secondly, in almost all trials the internal mammary nodes were irradiated, which results in significant radiation of the heart, yet these nodes are not irradiated in current practice either after breast conserving surgery or after mastectomy. ${ }^{5}$ The overview did find that radiotherapy produced substantial reductions in local recurrence, with three times fewer recurrences when radiotherapy was added to surgery. ${ }^{4}$

\section{Local recurrence is treatment failure}

As one of the aims of local treatment is to maintain local control of disease, recurrence represents failure of trèatment. Reported rates of local recurrence after breast conserving surgery and radiotherapy vary widely from $0 \%$ to $22 \%{ }^{67}$ This wide variation is partly explained by factors related to local recurrence. In order of importance these are completeness of excision; the presence of an extensive in situ component, defined as more than $25 \%$ of the main tumour mass being in situ with cancer also being present in situ in the surrounding breast tissue; lymphatic vascular invasion, which is visible microscopically; and high tumour grade. ${ }^{8}$ Young age (under 35 years) is also associated with a greater risk of local recurrence, but this is because younger patients are more likely to have high grade cancers with lymphatic vascular invasion and an extensive in situ component. ${ }^{9}$ To minimise local recurrence after conservative surgery, the surgeon must ensure that all invasive and non-invasive disease is completely excised. ${ }^{89}$ For patients at high risk of local recurrence, mastectomy with or without postoperative radiotherapy to the chest wall may be necessary. ${ }^{10}$ Systemic treatment also appears to have some impact on local recurrence. 9 This explains why the rate of recurrence in the national surgical adjuvant breast and bowel project was only $5 \%$ in women whose axillary nodes were invaded with cancer, all of whom received chemotherapy, compared with $12 \%$ in the node negative group. ${ }^{3}$

No group of patients has been identified in whom radiotherapy can be routinely omitted after breast conserving surgery, although there is anecdotal evidence that not all elderly patients may need it. ${ }^{11}$ An ongoing trial run by the British Association of Surgical Oncology is assessing the need for radiotherapy in small, low grade, node negative breast cancers, most of which are detected by breast screening. In contrast, radiotherapy after mastectomy can usually be avoided, provided that the patient is node negative or has had full axillary clearance and is not at high risk of local recurrence. ${ }^{12}$ Avoiding radiotherapy is particularly important 
when a patient has undergone immediate breast reconstruction, as even when radiotherapy is delivered over a longer period than normal it has a deleterious effect on the final cosmetic outcome.

Breast conserving treatment is usually offered only to patients with single tumours measuring less than $4 \mathrm{~cm}$ in diameter, because the cosmetic outcome of excising larger tumours is poor. However, in up to $80 \%$ of patients with large operable breast cancers and roughly $25 \%$ of patients with locally advanced breast cancers, breast conservation is possible if the size of the tumour is reduced by a course of primary systemic treatment. ${ }^{1314}$ This so called neoadjuvant therapy usually consists of combination chemotherapy, although hormonal treatment can also lead to significant reduction in the size of tumours if they have oestrogen receptors. ${ }^{15}$ If the patient has a complete clinical response after primary systemic treatment, the question then is whether she needs surgery or whether radiotherapy alone would be sufficient. The answer at the present time is that patients should have both surgery and radiotherapy for the following reasons. Firstly, over three quarters of patients with complete clinical responses have residual microscopic disease, ${ }^{13}$ which is sometimes extensive. Secondly, local recurrence after radiotherapy alone seems to be higher than that after surgery and radiotherapy. ${ }^{16}$ Thirdly, the histological status of lymph nodes at the end of primary systemic treatment is the most useful predictor of long term survival. ${ }^{17}$

Although there is no definite evidence that better local control is associated with improved survival, by reducing the rate of local recurrence in patients with operable breast cancer, local treatments do have an impact on patients' quality of life. The recent overview raises the possibility that, if deaths due to causes other than breast cancer can be limited better control of local disease might be translated into better overall survival. ${ }^{4}$

J MICHAEL DIXON

University Department of Surgery,

Honorary senior lecturer

Royal Infirmary,

Edinburgh EH3 9YW

1 Roberts J. Fraud in breast cancer trial shakes US. BMF 1994;308:809.

2 Christian MC, McCabe MS, Korn EL, Abrams JS, Kaplan RS, Friedman MA. The National Cancer Institute audit of the national surgical adjuvant breast and bowel project protocol B-06. $N$ Engl f Med 1995;333:1469-74.

3 Fisher B, Anderson S, Redmond CK, Wolmark N, Wickerman DL, Cronin WM. Reanalysis and results after 12 years of follow up in a randomised clinical trial comparing mastectomy with or without irradiation in the treatment of breast cancer. N Engl f Med 1995;333:1456-61.

4 Early Breast Cancer Triallists' Collaborative Group. Effects of radiotherapy and surgery in early breast cancer an overview of the randomised trials. NEngl f Med 1995;333:1444-55.

5 Bundred NJ, Morgan DAL, Dixon JM. ABC of breast diseases: management of regional nodes in breast cancer. $B M 7$ 1994:309:1222-5.

6 Schmidt-Ullrich $\mathrm{R}$, Wazer DE, Tercilla $\mathrm{O}$, et al. Tumor margin assessment as a guide to optimal conservation surgery and irradiation in early stage breast carcinoma. Int $\mathcal{F}$ Radiat Oncol Biol Phys 1989;17:733-8.

7 Locker AP, Ellis IO, Morgan DAL, Elston CW, Mitchell A, Blamey RW. Factors influencing local recurrence after excision and radiotherapy for primary breast cancer. Br f Surg 1989;76:890-4.

8 Dixon JM. Histological factors predicting breast recurrence following breast conserving therapy bstract. Breast 1993;2:197.

Kurtz JM. Factors influencing the risk of local recurrence in the breast. Eur $\mathcal{f}$ Cancer 1992;28: 660-6.

10 Sibbering DM, Galea MH, Morgan DAL, et al. Selection criteria for breast conservation in primary operable breast cancer. Breast 1995;4:232-3.

11 Veronesi U, Luini A, del Vecchio M, Greco M, Galimberti V, Merson M. Radiotherapy after breast-preserving surgery in women with localised cancer of the breast. N Eng $\mathcal{f}$ Med 1993;328:1587-91.

12 Sainsbury RJC, Anderson TJ, Morgan DAL, Dixon JM. ABC of breast diseases: breast cancer. $B M \mathcal{F}$ 1994;309:1150-3.

13 Bonnadonna G, Veronesi U, Brambilla C, et al. Primary chemotherapy to avoid mastectomy in tumors with diameters of three centimeters or more. I Natl Cancer Inst 1990;82:1539-45.

14 Singletary SE, McNeese MD, Hortobagyi GN. Feasibility of breast-conservation surgery after induction chemotherapy for breast cancer. Cancer 1992;69:2849-52.

15 Forrest APM, Anderson EDC, Gaskill D. Primary systemic therapy for breast cancer. In: Breast disease: new approaches Stewart HJ, Anderson TJ, Forrest APM, eds. Br Med Bull 1991;47: 357-71.

16 Mauriac L, Durand M, Avail A, Dilhuydy J-M. Effects of primary chemotherapy in conservative treatment of breast cancer with operable breast tumors larger than $3 \mathrm{~cm}$. Ann Oncol 1991;2 $347-54$

17 Cameron DA, Anderson EDC, Levack P, Forrest APM, Leonard RCF, Chetty U. Long-term follow up of neo-adjuvant therapy in operable breast cancer-an update of the original Edinburgh series. Breast 1995;5:240-1.

\section{Brachial plexus neuropathy after radiotherapy for breast cancer}

\section{Lower doses and surgical management of the axilla may be the answer}

It is tragic when patients are permanently harmed by a complication of treatment. One such complication, which has recently received publicity, is brachial plexus neuropathy after radiotherapy for early breast cancer. ${ }^{1}$ A group of women who perceived themselves damaged in this way formed a pressure group called RAGE (Radiotherapy Action Group Exposure). In response the Royal College of Radiologists commissioned an independent survey by two senior oncologists funded by the NHS Executive. ${ }^{2}$

The committee of RAGE received more than 1000 letters after publicity surrounding litigation and formed an action group with 800 members. Of 556 women who thought they had sustained nerve damage the college contacted those who had been treated at 15 representative centres. These women were asked if they would agree to have their medical records reviewed in order to establish whether they were suffering from a condition related to the disease process or to previous treatment, or both. It was essential to identify factors in the delivery of the radiotherapy or its association with surgery or chemotherapy that might have contributed to the neuropathy.

Against advice from their solicitors, 126 of the women agreed to have their records examined, and 48 (38\%) of them were found to have brachial plexus neuropathy due to radiotherapy. These patients had been treated during a 14 year period (1980-93) at 15 radiotherapy departments in
England and Wales. These centres gave radiotherapy to about 65000 women with operable breast cancer during this period. (It is not known how many of these also developed side effects.) Although 41 cases occurred during 1980-6, only seven patients had received treatment since 1986 . Since the median delay between treatment and the start of symptoms was 27 months, this implies a decline in incidence of neuropathy.

An extensive review of the factors associated with radiotherapy in breast cancer-associated surgery, chemotherapy, radiation dose, fractionation regimes, the position of the patient, the radiotherapy fields, and the treatment schedulelaid the main blame for the neuropathy on the planned movement of the patients' arms and bodies between radiotherapy to the breast and radiotherapy to the axillary and supraclavicular lymph nodes. Thirty four of 47 patients $(72 \%)$ moved in this way developed neuropathy, compared with only 12 of $51(24 \%)$ who were not moved. The high doses used to treat the axilla in the past were a secondary cause. ${ }^{3}$

While radiotherapy has an important effect in preventing local recurrence and thus improving quality of life, a recent overview shows no significant impact on 10 year survival. ${ }^{4}$ Indeed, a 5\% reduction in deaths from breast cancer seems to be counterbalanced by an increase in deaths from other causes. However, studies with longer follow up have shown a significant trend towards improved survival, suggesting that 